\title{
Miriana Vilke \\ CHILDREN AND FOREIGN LANGUAGES IN CROATIAN PRIMARY SCHOOLS FOUR YEARS OF A PROJECT
}

\section{Introduction}

7 he ultimate aim of starting the work on this project was a vision of future native 1 speakers of Croatian who could use one of the widespread languages of western civilization in their life and work. This is why we started with four languages: English, French, German, and Italian. This is why we moved the start of the process of learning these languages from ten to six or seven years old. The pragmatic idea behind the undertaking was - why not use the period of human life when the child has plenty of good will and time, when the daily chores and duties are not pressing and when the child is at its best to acquire certain aspects of language performance.

It would provide enough time for the child to reach a high standard of proficiency by the end of secondary education when the need to use foreign language actually arises.

We actually started to look for an optimal age to begin institutionalised learning of foreign languages in the seventies when in a series of "Natural experiments" we tested the phenomenon of language-learning blocks which according to Lenneberg (1967) appear at puberty. A comparison between 8-year-old and 18-year-old beginners of English showed that the former group had advantages especially in pronunciation. We turned to this age group equipped with Piaget's rich evidence of their characteristics and abilities. (Vilke, 1976a). To discover more about the potential achievements of children of this age we based our investigations on the evidence, available at the time, of children's acquisition of their own language as well as a second and foreign language. Our evidence comes from varied sources such as psychology, developmental psycholinguistics, sociolinguistics, interlanguage studies, morpheme studies, and last but not least, the experience of teachers who worked with this age group. They always seemed to claim that the results of work could be very good if the children were approached in the right way (Vilke, 1976b).

But what is the right way? Do we know enough about either the language or the child to choose the right way? Chomsky himself, the supreme authority of the time on any study of language acquisition, thought we did not. I refer here to his well known statement that neither linguistics nor psychology can help to improve teaching of languages (Chomsky, 1968). However, the need to communicate in a widespread lan- 
guage for a small language community like Croatia seemed to become more and more important as time went by. So, our first pilot project started in 1973 and our 8-year olds who started their English or German at the age of 8 were quite successful. The project did not bring about fabulous results for reasons that now seem quite transparent but it supplied us with insights that helped us to shape the present project (Vilke, 1979). Consequently, when we started in 1991, it was not from scratch.

We directed our efforts in two interrelated directions. One was the investigation of different aspects of children's performance, conducted by applied linguists and psychologists using the methods of research employed in the field - tests, questionnaires, and interviews. The other was the actual work of teachers in the classroom. The teachers were encouraged to use their own creative ways of teaching, depending on their intuition and the requirements of the individual groups of learners, as well as their own (the teachers') personality traits. However, there were a few conditions that had to be fulfilled. Namely, the teachers should make children happy and relaxed during the classes to secure receptive learning with no "weeds and big stones" to struggle with - to use Curran's metaphor (Curran, 1972).

We have now completed four school years of the work in the Project. The first generation of our learners have had their foreign language for five periods a week in the first and second grade and four periods a week in the third and fourth grade in groups of 12 to 15 learners. About 2,000 learners of English, French, German, and Italian have been taught in this way in Zagreb, with addition of some classes in Rijeka, Split, Pula, and Osijek, which covers approximately 1,000 more children. It is a small sample of learners if any generalizations are attempted, but on the other hand, it is easier to conduct systematic observation, exchange ideas and apply different measuring instruments if the number of learners is limited. We are well aware that whatever results are achieved they will be valid in our sociocultural environment while in any other area they will have to be verified as many extralinguistic factors that influence the teaching are present in any class situation. However, it is our hope that when our educational authorities decide to introduce foreign languages into the first grade of the primary school on a large scale, we shall be ready to offer a rational, minutely elaborated approach.

After four years of joint work of practising teachers and researchers I trust that we can offer tentative answers to several questions. They will be discussed by contributions in all four Project languages on the pages of the present publication which is actually a follow up of the book CHILDREN AND FOREIGN LANGIAGES/LES ENFANTS ET LES LANGUES ETRANGERES, (University of Zagreb, Faculty of Philosophy, Zagreb, 1993).

The presentation that follows will deal with my own views of what has been achieved so far. 


\section{Have we found an optimal age to start?}

It seems that the first grade (age 6 to 7 ) is a good time to start the long process of learning a foreign language. Many theoreticians support this thesis directly or indirectly. Piaget's work on cognitive development of children provides a framework offering clues for organization of teaching that would be appropriate for the level of intellectual maturity of learners (Piaget, 1973).

Lenneberg (1967), in his time, concentrated on the prepuberty phase, when for biological reasons children can learn foreign languages without a foreign accent. The "Sensitive period hypothesis" and its advocates suggest that this period in human life should be used to start mastering a foreign idiom. Krashen (1973) claims that an early start proves good in the long run.

R. Bley-Vroman (1989), who advanced his "Fundamental difference hypothesis", claimed that the domain-specific language acquisition system of children ceases to operate in adults. While adults possess native language knowledge and are able to operate general problem-solving systems "children have a crucial something such as personality state, attitude, degree of motivation, stage of ego-development or socialization, way of interacting or the like," (ibid., p. 51). Around puberty a general ability to deal with abstract formal systems is developed. This is the onset of Piaget's stage of formal operations, and consequently it could offer an ideal time to fill in the gaps in children's simplified systems of interlanguage that they developed in earlier years extremely successfully. Nevertheless, children are able to deal with the language in a kind of limited cognitive way. Bley-Vroman offers an acceptable explanation to that, claiming that in the stage of Piagetian concrete operations the language-specific cognitive system is the only cognitive module capable of dealing with language.

The Project experience supports the thesis. Children from 7 years on are capable to perform cognitive operations in a language, so one of the tasks of the Project was to find out more about that.

Our efforts were directed towards defining this "crucial something" in Bley-Vroman terms that makes children so successful in operating the phonological system of a foreign language and in communicating freely and expressively.

Adults give priority to understanding the subtle processes of foreign language grammar. Let us insist on their accuracy of expression based on analysis, synthesis, and other cognitive operations. They will be able to use such operations much more successfully if they have had a number of years of free and genuine communication as children.

According to the experience of Project teachers the work with 6-7-years-olds is both extremely difficult and very rewarding for the teacher who must very often play an additional role - that of a substitute parent, as the children still do not know the 
rules of the game that are feasible in the classroom, and some of them are very slow and not sufficiently socialized.

In spite of all this, in a recent discussion of that issue, all our teachers who worked with the first grade declared that this was the time to start. During this period, the children go through a kind of novice stage and come to the second grade prepared for more serious work.

On the theoretical ground we investigated whether the process of learning a foreign language exerted any kind of "balance effect," that is, played a negative influence on learning other subjects, especially Croatian, and none was observed. On the contrary, children learning a foreign language showed more understanding of language as a system, which is in accordance with the well-known Vigotsky's thesis (Vigotsky, 1962).

\section{What characteristics and abilities of children should be taken into consideration?}

One certainly should not overlook the fact that there are individual differences in the way children develop language. Dealing with the first language acquisition Ann Peters (1977) suggested that there may be three types of language learners: 1. those who use an analytic approach (starting with the parts and building up the whole) 2. those who use a gestalt approach (from the whole to the various parts) 3. those who use both an analytic and a gestalt approach. Although the transfer of theories from L1 acquisition to the field of L2 in the past often proved to be counter-productive, the differences should not be neglected. However, it may be that in an FL class, where the input is structured and controlled, one should be more careful about the differences in the affective and attitudinal domain (see the chapters by Mihaljević Djigunović).

What we can accept without hesitation is Arnberg's statement that the development of the system of the language involves an interaction of the child's linguistic knowledge about the non-linguistic context and strategies used by the child in understanding or using the language (Arnberg, 1987).

Some of the characteristics of children at the stage of concrete operations, that can be attributed to the majority of children are included in the following. These must be accepted as important in planning any activity with the young learners:

- Children of this age become emotionally attached to the teacher to such an extent that it may become a decisive factor in their attitude towards the foreign language they are learning. As a rule they either like their teacher very much, or dislike her (him) completely.

- They should experience the process of learning English as a kind of game to which they are eager to contribute motorically, emotionally, and intellectually. 
- Some children are extremely shy at the beginning and they must be given an opportunity to join in when they are ready, not when it pleases the teacher.

- Seven-year-olds often show a possessive attitude towards the teacher if they like her, but are not particularly interested in their peers in the class. Some children are not interested in making friends at that age.

- They cannot concentrate on one activity for more than five to ten minutes after which time they become tired and bored.

- With many children their imagination has yet to be aroused. I have observed first graders practising the structure "I can see", looking through the binoculars and giving way to their imagination by imagining all sorts of creatures and things from extraterrestrials and flying saucers to dinosaurs and helicopters.

\section{The teacher}

Children need a leader for all their games, that is teachers that will dance and sing with them, play with them, draw and act with them - which is demanding not only intellectually and emotionally, but is also tough physical work. Few people realise what traps for teachers are hidden in the acronym TPR (total physical response). The teacher of a 7-year-old should know her English extremely well, especially on the communicative and phonological side, as in many cases she will be the only model to imitate.

She should love both the children and the work she is doing if she wants to be successful. At one of the Project meetings I have suggested that the teacher's behaviour should be that of TER - total emotional response - and the acronym was accepted and started to be used, showing that there was an empty slot in the system which was filled in readily.

She should be creative but this creativity should emerge from her personality traits, in other words, she should be convinced that what she does is worth doing and have her own justification for it. I shall try to illustrate it: Teacher A was a rather strict person, a perfectionist, who demanded much from her pupils from the very beginning, for example she insisted on accuracy of expression, especially that of pronunciation. Both she and her pupils used a lot of energy in English classes. Nevertheless, they formed a happy and successful group, as the children very quickly accepted the rules of the game the teacher advanced. Teacher B was rather strict with herself, but permissive with the children, she immersed them in a rich language bath to which they orally responded when they were ready. There was never a lack of volunteers in the class who wanted to participate in different (language) games. Both groups of learners are now in the fourth grade, both like their English and their teacher. Which group is linguistically better? We shall find out in a couple of years when the corpus of their knowledge 
is analysed if it is important at all. Both teachers believe in their respective approaches and both are accepted by the children, who are highly motivated to continue.

\section{Four years of observing different teaching procedures and activities}

Four years of work provided us with the ideas of how to organize teaching to involve our young learners in listening and speaking, to shield shy students from the embarrassment of speaking in front of the class and to provide a safe, informal, and comfortable atmosphere. A number of contributions in this book deal with the different aspects of teaching techniques so I shall limit myself to highlighting two ways of teaching that proved to be very productive.

\section{Content-related teaching}

In content-related teaching the teacher is not dealing with language that is isolated and reduced to small pieces and the learners see the language and the concepts to be learned as part of an integrated whole. We fully agree with Curtain and Pesola (1994), who see the success of content-related teaching in the fact that "[i]n order for communication to take place, there must be some knowledge or information to be shared. Communicative competence can be developed as students feel the need to exchange the information with one another or with the teacher in a setting that has significance for all of the participants in the communication" (p.151). The teachers in the Project organized this kind of work in collaboration with the class teacher following class curriculum and reinforcing the children's work on mathematics and science and content of other school subjects areas, thus helping the learners and making new concepts less language dependent and language tasks more cognitively engaging.

\section{Story-telling}

Story-telling also deserves to be specially mentioned as it was practiced practically from the first day of the course. It was always carefully graded in accordance with the linguistic and cognitive level of the students, involving in some cases just listening, and in the others TPR, role playing, dramatization and even writing children's own stories, thus evoking children's creativity and stirring their imagination.

In recent years stories have been recognized as a very powerful tool in developing children's communicative as well as language competence both in the first and the second language. Bruner (1990) even claims that our perception of the world is shaped by the stories to which we are exposed and which we have internalized. Stories have 
shown to be a very valuable aid in familiarizing the young learners with the ideas and values of the target culture, as they need very little language background to comprehend the myths, legends, and fairy tales popular in the target culture.

\section{Some ideas on selection of the teaching input}

Should the linguistic material presented to the children be selected and graded according to accepted pedagogical principles - from known to unknown, from simple to more complex, or should they be exposed to the language input no matter how complex it may be?

From second language acquisition studies the evidence was advanced that the language input was what really mattered (Dulay and Burt, 1973) and that children would pick up linguistic structures without teaching. This is probably true to a certain extent in second language situations when the children are exposed to the second language and its culture for a long time every day, but it certainly does not work in traditional school situations. In our Project the situation has been half way between the second and foreign language: five periods of weekly practice with the foreign language in groups of 12 to 15 learners gives ample time for some linguistic structures to be internalized spontaneously. Nevertheless, the fact remains that some parts of the linguistic system are remembered and used much more readily than others. Learning could be largely facilitated if structures that cause difficulty were avoided at this young age, or at least if the teachers could get hints when not to insist on their use. This is why we attempted some comparative cross-sectional studies in English, French, and German. Italian was not included for some technical reasons.

\section{The first study}

In order to investigate the use of personal pronouns by the children in the three languages four groups of Croatian learners were tested on their use of male and female personal pronouns $3^{\text {rd }}$ person singular.

Subjects were: 88 learners of English $-3^{\text {rd }}$ grade

50 learners of English $-4^{\text {th }}$ grade

32 learners of French $-3^{\text {rd }}$ grade

13 learners of German $-3^{\text {rd }}$ grade

The task was to respond to two sentences written in Croatian:

Vesna je gladna. [Vesna is hungry] Ona jede jabuku. [She is eating an apple. Mirko je žedan. [Mirko is thirsty] On pije koka kolu. [He is drinking a coca-cola] 
The examinees were asked to translate these sentences into their respective foreign language and say the translation to the teacher. The task was performed individually, and the learners could not see or hear each other's answers.

The pronouns were selected as in an earlier experiment I have observed (Vilke, 1988) that children learning English were reluctant to use he or she and preferred using the nouns instead, although most of them understood what he and she stand for. In his inaugural article on interlanguage Selinker (1972) mentioned as typical the mistake of Croatian speakers of English who use he instead of she in many cases. On the other hand C. Chomsky (1969) found that the process of pronominalization was not yet accomplished in English as a first language by the age of 6 or 7. In the present experiment we wanted to find further clues about the children's erroneous use of the pronouns, in case they do make errors after a relatively long practice. A further question we wanted to be highlighted relates to difficulties. Are they L1 specific, or L2 specific, or due to the level of cognitive maturity of children of that age? This is why our investigation included English, French and German.

The results were the following:

English - fourth grade

he and she correctly used by 46 learners

he instead of she by 4 learners

English - third grade

he and she correctly used by 81 learners

he instead of she by 7 learners

French - third grade

Il and elle correctly used by 19 learners

Il instead of elle by 12 learners

German - third grade

er and sie correctly used by all 13 learners

The teachers' comments on the general use of the personal pronouns were that at the beginning - that is in the first two grades - there was a certain confusion which gradually diminished. Thus, in the third and fourth grade, if there are any difficulties they are due to slips (the learners usually self-correct themselves.)

A higher number of learners who used il instead elle was observed only in French, but it cannot be taken as significant because the sample was too small.

The teachers reported the avoidance of using $3^{\text {rd }}$ person personal pronoun plural, instead of which the learners prefer using personal names. 
Teaching implications - at this early age, especially in the first two grades, teachers should not insist on accuracy in using pronouns as it seems to be in connection with the gradual language consciousness-raising, which advances with age.

In English, Croatian learners had also problems with it for inanimate and much rather used the nouns. This mistake can be attributed to the negative transfer from Croatian as we have grammatical gender and inanimates have masculine, feminine or neutral gender. To avoid the erroneous usage learners of English seem to be on a safer ground if they use the nouns.

\section{The second study}

To examine the special concepts expressed by the prepositions the learners of the three respective languages were chosen.

Their task was to play the game "Where is everything?". They were asked to describe the position of different objects in the class so that we could find out which preposition was most frequently used and whether there was any "universality" of usage across the three languages. It was again an individual procedure: one examiner one examinee. The examinee was asked to describe where different objects in the class were placed. Subsequently, the examiner would write down their answers and then list six of the most frequently used prepositions in their order of frequency.

The tables of frequency are included in the following.

ENGLISH 138 learners

Total number of times of the most frequently used prepositions -659

\begin{tabular}{|c|c|c|c|}
\hline & & correctly & incorrectly \\
\hline $\mathrm{ON}$ & $269(40.8 \%)$ & $261(97 \%)$ & $8(3 \%)$ \\
\hline IN & $125(19.0 \%)$ & $107(85 \%)$ & $18(15 \%)$ \\
\hline UNDER & $94(14.3 \%)$ & $81(86 \%)$ & $13(14 \%)$ \\
\hline BEHIND & $74(11.2 \%)$ & $62(84 \%)$ & $12(16 \%)$ \\
\hline $\begin{array}{l}\text { IN FRONT } \\
\text { OF }\end{array}$ & $51(7.7 \%)$ & $49(96 \%)$ & $2(4 \%)$ \\
\hline BETWEEN & $46(7.0 \%)$ & $46(100 \%)$ & - \\
\hline
\end{tabular}


FRENCH 32 learners

Total number of times of the most frequently used prepositions -103

\begin{tabular}{l|l|l|l} 
& & \\
SUR & $37(35.9 \%)$ & $27(73 \%)$ & $10(27 \%)$ \\
SOUS & $22(21.4 \%)$ & $14(64 \%)$ & $8(36 \%)$ \\
DANS & $22(21.4 \%)$ & $19(86 \%)$ & $3(14 \%)$ \\
DERRIERE & $9(8.7 \%)$ & $6(67 \%)$ & $3(33 \%)$ \\
A COTE & $7(6.8 \%)$ & $7(100 \%)$ & - \\
DEVANT & $6(5.8 \%)$ & $3(50 \%)$ & $3(50 \%)$ \\
\hline
\end{tabular}

\section{GERMAN 13 learners}

Total number of times of the 5 most frequently used prepositions -36

\begin{tabular}{l|l|l|l} 
& & & \\
AUF & $19(52.8 \%)$ & $16(84 \%)$ & $3(16 \%)$ \\
UNTER & $10(27.8 \%)$ & $10(100 \%)$ & \\
IN & $4(11.1 \%)$ & $4(100 \%)$ & \\
NEBEN & $2(5.5 \%)$ & $2(100 \%)$ & \\
HINTER & $1(2.8 \%)$ & $1(100 \%)$ & \\
& & & \\
\hline
\end{tabular}

On in English, auf in German and sur in French are the most frequently used prepositions, followed by in in English, dans in French and unter in German.

$O n$ and its equivalent in other languages is definitely the most frequently used preposition. The meaning of the prepositions that follow does not conform to a regularity among the languages. We can always say, of course, that it is dependent on the amount of practice different teachers allowed for different prepositions, but it seems to me that the reason is more conceptual than linguistic or pedagogical. Eleanor Rosh (1978), who proposed the Prototype theory, argues that people always consider some members of a category more typical than other members. So, for example, they consider robins and sparrows typical birds, but not chickens and penguins. Such prototypical members enter more easily into cognitive operations, such as constructing new sentences, than do peripheral members. For our young learners on and in and their translational equivalents are prototypical prepositions as opposed to in front of, devant or hinter. 
The Prototype theory could become a valuable tool in searching for explanation why certain lexical items are much more difficult for children to remember and use in cases when neither linguistic nor affective factors seem logical. So, for example, brown is always a colour that young children would not use if they had a choice. Moreover, it is much more difficult to remember than violet, for example. Is it because of its lack of "colourness" and consequently its peripheral status, or because of its low affective value? (Children simply do not like brown!).

The Prototype theory is not in contradiction with the theory of markedness (Fergusson, 1984), which has been carried over into syntax and semantics by several scholars. Slobin (1985) claimed, for example, that due to the structure of the human perceptual and cognitive apparatus, certain morphological and syntactic patterns are more natural or less marked than others and that these patterns emerge first in the child's language. He states (ibid, p. 1160), "([s]emantic and formal) entities are arrayed in an accessibility hierarchy according to which some notions and forms are likely to emerge earlier (...) than others."

Although it may seem a purely academic issue, it could have a very serious bearing on the selection and contents of the teaching materials for young children. What I mean is that one should identify prototypical (or unmarked) elements of language and give them priority in the language syllabus prepared for young children.

Research of this type is extremely demanding and time consuming but we plan to conduct more of it through doctoral and master's theses of young people interested in the field. It is our firm belief that, in the long run, the more insight we have into the cognitive and other processes at work in the course of acquiring a foreign language the more successful the work in class will be.

\section{To sum up}

The work on the Project so far has shown once again that children of $6+$ can learn foreign languages even in a school environment provided teaching is shaped according to the psychomotoric and intellectual requirements of this complex age.

The foreign language can become an integral part of the learner's work in school, hopefully, the most enjoyable part with the teacher's adequate attitude towards it and with the positive attitudes of all concerned, that is, the class teacher, parents and principal. The mass media, especially TV and video, will do their part of the job to help the teacher. Integration into the primary curriculum will be part of a natural process. Some subjects such as maths, drawing, physical training, etc., lend themselves ideally to a start in a different language. A relatively large number of contact hours should offer ample opportunities for all basic language skills to be used. The order of intro- 
ducing them should - according to our Project's experience - remain traditional. Listening to the language input first, responding orally when the children are ready for it, next reading and finally writing, which corresponds to the process of a child becoming literate in Croatian. No strict prescriptions concerning the time of introducing reading and writing should be given and it will have to be left to the discretion of the teacher as children differ significantly regarding their maturity. If children are exposed to efforts they are not yet ready to accept, their motivation may suffer dangerously. It is essential that the entire process of learning be based on receptive learning rather than defensive - to use Curran's terms, that is, free from anxiety and stress, so often present in traditional school activities.

The entire adventure of introducing English into the first form of primary school should lead to one goal - to make the child accept it as an alternative medium of communication through a natural and enjoyable process. This is much easier said than done and will require a lot of hard work on the part of many people, but it seems that the results achieved so far show that we are on the right track.

\section{Bibliography}

Arnberg, L. (1987). Raising children bilingually. Clevedon: Mutilingual Matters.

Bley-Vroman, R. (1989). What is the logical problem of foreign language learning?. In S.M.

Gass \& J. Schachter (Eds.), Linguistic perspectives on second language acquisition (pp. 44-

68). Cambridge: Cambridge Universty Press.

Boyd, G.A. (1976). Linguistics in the elementary school. Itasca: Peacock.

Brown, R. (1973). A first language. Cambridge, MA: Harvard University Press.

Bruner, J. (1990). Acts of meaning. Cambridge MA: Harvard University Press.

Burstall, C., Jamieson, S., Cohen, S. \& Hargreaves, M. (1974). Primary French in the balance. Slough: NFER.

Chomsky, C. (1969). The acquisition of syntax in children from 5 to 10. Chicago: MIT Press. Chomsky, N. (1968). Interview to "Listener", 30.5.

Churran, Ch.A. (1972). Counselling-Learning: A whole person model for education. New York: Grune and Straton.

Curtain, H., and Pesola, C. (1994). Languages and children: Making the match. White Plains, N.Y.: Longman.

Dulay, H. \& Burt, M. (1972). Goofing: an indicator of children's second language learning strategies. Language Learning 11, 135-52.

Dulay, H. \& Burt, M. (1973). Should we teach children syntax?. Language Learning 23, $245-$ 58.

Dulay, H. \& Burt, M. (1974a). Errors and strategies in child second language acquisition. TESOL Quarterly 8(2), 129-136. 
Dulay, H. \& Burt, M. (1974b). A new perspective on the creative construction process in child second language acquisition. Language Learning 24, 253-79.

Ferguson, C. (1984). Repertoire universals, markedness, and second language acquisition. In W.E. Rutherford (Ed.), Language universals and second language acquisition (pp. 247-258). Amsterdam: John Benjamins.

Krashen, S. (1973). Lateralization, language learning and the critical period. Language Learning 23, 63-74.

Lamendella, J. (1977). General principles of neurofunctional organization and their manifestation in primary and non-primary language acquisition. Language Learning 27, 155-97.

Larsen, D. \& Smalley, W. (1972). Becoming bilingual. New Canaan, CN: Practical Anthropology.

Lee, W. (1977). For and against an early start. Foreign Language Annuals 3, 263-270.

Lenneberg, E. (1967). Biological foundations of language. New York: J. Wiley.

Long, M. (1988). Maturational constraints on language development. University of Hawaii Working Papers in ESL 7, 1-53.

Peters, A. (1981). Language learning strategies: does the whole equal the sum of the parts? Language 53, 560-573.

Piaget, J. (1952). The origins of intelligence in children. New York: International Universities Press.

Piaget, J. (1954). The construction of reality in the child. New York: Basic Books.

Piaget, J. (1958). Six psychological studies. London: University of London Press.

Piaget, J. (1973). Memory and intelligence. London: Routledge and Kegan Paul.

Roberts, J.T. (1973). The LAD hypothesis and L2 acquisition: The relevance of the former for the letter. Audio-visual Language Journal 11(2), 97-112.

Rosh, E. (1978). Principles of Categorization. In E. Rosch \& B.B. Lloyd (Eds.), Cognition and categorization (pp. 27-48). Hillsdale, NJ: Lawrence Erlbaum Associates.

Slobin, D. (1985). Crosslinguistic evidence for the language-making capacity. In D. Slobin (Ed.) Crosslinguistic study of language acquisition (vol 2, pp. 1157-1256). Hillsdale, NJ: Lawrence Erlbaum.

Spicer, A. (1978). The early teaching of modern languages. Paper presented at the AILA congress, Montreal, August 1978.

Stern, H.H. (1963). Foreign languages in primary education. Hamburg: UNESCO Institute for Education.

Stern, H.H. (1969). Languages and the young school child. Oxford: Oxford University Press.

Van Parreren, C.F. (1976). The psychological aspects of the early teaching of modern languages. IRAL 14(2), 135-43.

Vilke, M. (1976 a). The age factor in the acquisition of foreign languages. Rassegna Italiana di Linguistica Applicata, No. 2/3.

Vilke, M. (1976 b). Implications of the age factor on the process of acquisition of an L2. SRAZ 41-42, 87-104.

Vilke, M. (1979). English as a foreign language at the age of eight. SRAZ 24, 297-336. 
Vilke, M. (1988). Some psychological aspects of early second language acquisition. Journal of Multilingual and Multicultural Development $9(1$ \& 2), 115-128.

Vilke, M. (1995) Early foreign language teaching in Croatian primary schools. In M. Vilke \& Y Vrhovac (Eds.) Children and Foreign Languages (pp. 10-27). Zagreb: Faculty of Philosophy, University of Zagreb.

Vygotsky, L. (1962). Thought and language. Chicago: MIT Press. 